\title{
HIV und Lunge
}

\section{Lange ${ }^{1}$ \\ B. Schaaf ${ }^{2}$ \\ K. Dalhoff ${ }^{2}$}

HIV and Lung

\section{Zusammenfassung}

Der Verlauf der HIV-Infektion ist durch eine progrediente Immundefizienz und ein gesteigertes Risiko für die Entwicklung opportunistischer Infektionen und Neoplasien gekennzeichnet. Infektionen der Lunge spielen dabei eine besondere Rolle, da die Atemwege ständigem Kontakt mit Mikroorganismen aus der Atemluft ausgesetzt sind. Neben dem Spektrum der Erreger ambulant erworbener Pneumonien treten mit zunehmender Immunschwäche auch Infektionen durch Mikroorganismen auf, die von Defekten der zellulären Immunabwehr profitieren. Hierzu gehören u.a. Infektionen mit Pneumocystis jirovecii, nicht-tuberkulösen Mykobakterien und viralen Erregern. Im Gegensatz dazu tritt die Tuberkulose auch schon in frühen Stadien der HIVInfektion gehäuft auf. Als Folge der HIV-Pandemie ist die Inzidenz der Tuberkulose daher in vielen Lðndern wieder stark angestiegen. In den vergangenen Jahren ist es aber durch den Einsatz einer kombinierten antiretroviralen Therapie (ART) in den industrialisierten Ländern gelungen, die HIV-assoziierte Morbidität und Mortalität drastisch zu senken. Als Folge der Immunrekonstitution unter ART ist damit auch die Inzidenz pulmonaler Koinfektionen in Ländern, in denen diese Therapien verfügbar sind, deutlich zurückgegangen.
Institutsangaben

${ }^{1}$ Medizinische Klinik, Forschungszentrum Borstel (Direktor: Prof. P. Zabel)

${ }^{2}$ Medizinische Klinik III, Universität Lübeck (Direktor: Prof. P. Zabel)

Anmerkung

C.L. und B.S. waren in gleichem Umfang an dem Manuskript beteiligt.

Widmung

Herrn Prof. H. Magnussen zum 60. Geburtstag gewidmet.

Korrespondenzadresse

Prof. K. Dalhoff · Medizinische Klinik III, Universität Lübeck · Ratzeburger Allee 160 23538 Lübeck ·

E-mail: klaus.dalhoff@uni-luebeck.de

Eingang: 10. April 2004 · Nach Revision angenommen: 15. Mai 2004

Bibliografie

Pneumologie 2004; 58: 416-427 • @ Georg Thieme Verlag KG Stuttgart · New York

DOI $10.1055 / \mathrm{s}-2004-818502$

ISSN 0934-8387
HIV-infection is characterized by a progressive immunodeficiency that predisposes affected persons to opportunistic infections neoplasias. Pulmonary co-infections play a key role in HIVairways are constantly exposed to aerosolized persons with HIV-infection are vulnerable to infections with organisms that profit from the progressive cellular immune deagain in many areas of the world. The advent of antiretrovira therapies (ART) in recent years had resulted in a dramatic decrease of HIV-related morbidity and mortality in industrialized countries. As a result of the reconstitution of the immune-system under ARTs the incidence of pulmonary co-infections has also declined substantially in persons living with HIV in countries where these therapies are available. 
Im Herbst 1982 wurde erstmals über eine Häufung von zwei bis dahin sehr seltenen Erkrankungen in nordamerikanischen Großstädten berichtet, dem Kaposi-Sarkom und der Pneumocystis carinii Pneumonie (PCP). Damit stand eine Lungenentzündung am Beginn der Entdeckung einer der folgenreichsten Epidemien, die am Ende des 20. Jahrhunderts eine Renaissance der Infektiologie eingeleitet hat [1]. In den westlichen Industrieländern konnte durch die rasche Entdeckung des der Erkrankung zugrundeliegenden Humanen Immundefizienz Virus (HIV), die Entwicklung wirksamer antiretroviraler Kombinationstherapien (ART) und breit angelegte Aufklärungskampagnen die Ausbreitung der HIVEpidemie weitgehend eingedämmt werden. Allerdings ist die Morbidität weiterhin hoch, da bei stabiler Inzidenz die Prävalenz aufgrund der verbesserten Prognose noch steigt, und die Erkrankung nimmt erhebliche Ressourcen der Gesundheitssysteme in Anspruch [2]. Global gesehen ist die Situation wesentlich dramatischer einzuschätzen: es handelt sich um eine unverändert aktive Pandemie mit Prävalenzen von über 30\% HIV-infizierter Personen in einigen Ländern des südlichen Afrikas und inzwischen auch rascher Ausbreitung der Infektion in Osteuropa.

\section{Management der HIV-Infektion}

Die Prognose der HIV-Infektion hängt heute weitgehend von der lokalen Verfügbarkeit und dem Ansprechen auf die antiretrovirale Therapie (ART) ab. Zahlreiche Studien belegen die Wirksamkeit der ART. Die Kombination von zwei Nukleosidanaloga beeinflusst die Mortalität bereits signifikant [3,4]. 1996 wurde gezeigt, dass die Zugabe eines Proteaseinhibitors die Mortalität zusätzlich deutlich senkt [5]. Seitdem gilt die Kombinationstherapie mit mindestens drei Substanzen als Standard. Die Kombinationstherapie führt neben der Reduktion der Mortalität und der Häufigkeit der Krankenhausaufnahmen auch zu einem Rückgang der AIDS definierenden Erkrankungen (Abb. 1) [1,6,7]. Die Inzidenz der AIDS definierenden Erkrankungen, insbesondere der opportunistischen Infektionen reduzierte sich in Europa von $1994-1998$ von 30,7 auf 2,5 pro 100 Patientenjahre [8]. Dieser Effekt ist anhaltend, denn trotz möglicher Langzeitnebenwirkungen und Resistenzentwicklungen führen die Kombinationstherapien auch nach mehrjähriger Einnahme zu einem Rückgang der Mortalität [7].

\section{Indikation zur antiretroviralen Therapie}

Die Indikation für den Therapiebeginn wird von der Klinik, der Zahl der CD4+ T-Lymphozyten (CD4-Zellen) und der HIV-RNAKonzentration im Plasma (Viruslast) bestimmt. Wichtigstes Therapieziel ist die Lebensverlängerung des Patienten bei möglichst guter Gesundheit und Lebensqualität. Konsens besteht darüber, dass symptomatische Patienten insbesondere im WHO-Stadium C (AIDS) behandelt werden sollten. Da z.B. ein Herpes Zoster (Stadium B) oder eine Tuberkulose (Stadium C) auch bei gutem Immunstatus auftreten können, kann im Einzelfall eine abwartende Haltung gerechtfertigt sein (s.u.). Empfehlungen der Fachgesellschaften zum Therapiebeginn, die sich auf CD4+ T-Zellzahl und Viruslast beziehen, sind uneinheitlich. Je niedriger die Zahl der CD4+-Zellen und je höher die Viruslast ausfallen, umso höher ist das Risiko, AIDS-definierende Erkrankungen zu entwickeln $[9,10]$. Hiergegen muss jedoch das Risiko von Langzeittoxizitäten und der Entwicklung von Resistenzen unter einer ART abgewo-
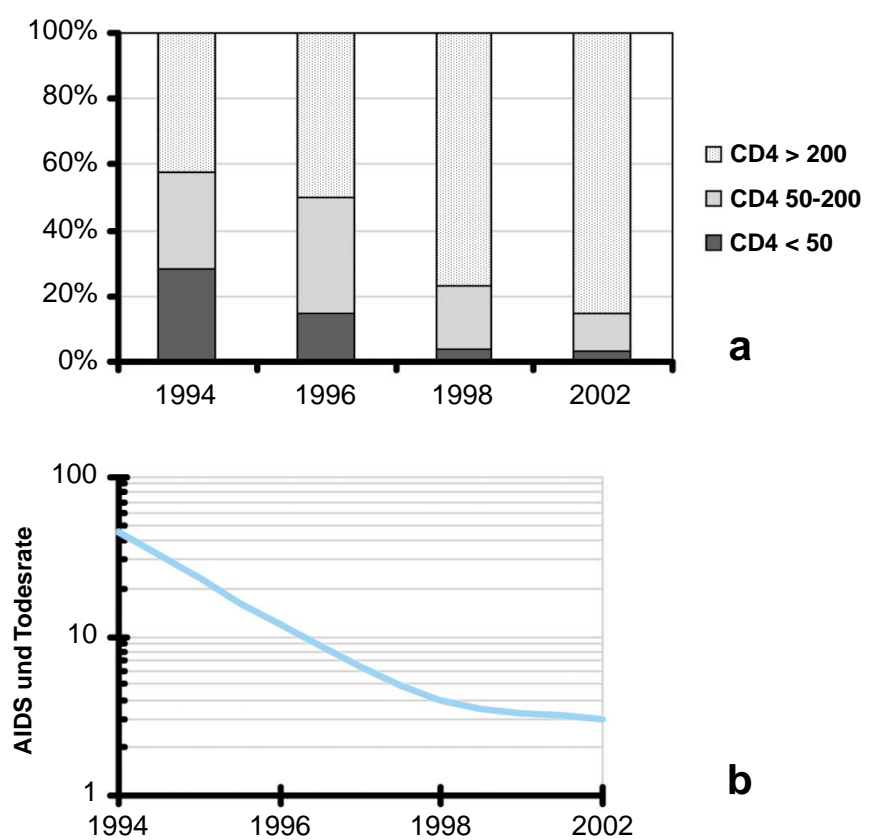

Abb. 1 (modifiziert nach [26]): Europaweite Kohortendaten (Euro SIDA) von 9803 HIV-Patienten im Zeitraum 1994 bis 2002: Die Einführung der ART hat zu eine dramatischen Verbesserung des Immunstatus und der Mortalität geführt. 1994 hatten fast $60 \%$ der Patienten einen schweren Immundefekt mit CD4+-Zellzahlen unter 200/ $\mu$ l, davon $28 \%$

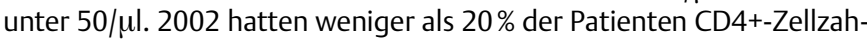
len unter $200 / \mu \mathrm{l}$ und nur 2,6\% weniger als $50 / \mu \mathrm{l}$ (a). Gleichzeitig zeigt sich eine Reduktion des kombinierten Endpunkts AIDS und Tod von 43,5 pro 100 Patientenjahre auf unter 3 pro 100 Patientenjahre (b).

gen werden. Einigkeit besteht darin, dass aufgrund des hohen Risikos Patienten mit weniger als $200 \mathrm{CD} 4+-$ Zellen/ $\mu$ l eine Therapie angeboten werden muss. Da keine Studie eindeutig den klinischen Nutzen der antiretroviralen Therapie bei Zellzahlen über

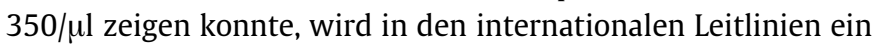
abwartendes Verhalten empfohlen [11,12]. Eine Grauzone besteht für Patienten mit CD4+Zellzahlen zwischen 200-350/ul. Therapienaive Patienten mit einer hohen Viruslast oder raschem Abfall der CD4+Zellen sollten in kurzen Abständen kontrolliert werden, um ggf. eine ART kurzfristig einzuleiten. Weitere Indikationen für eine antiretrovirale Therapie sind die vertikale Transmissionsprophylaxe in der Schwangerschaft und die Postexpositionsprophylaxe. Die akute HIV-Infektion ist zwar in $40-90 \%$ symptomatisch, wird aber aufgrund der Ähnlichkeit mit „grippalen" Infekten und initial negativen Antikörpertitern (aber positiver HIV PCR) meist übersehen [13]. Ob eine Therapie vor Serokonversion die spezifische Immunantwort erhält und zu einer langfristigen Virussuppression führt, ist unklar [14]. Patienten mit akuter HIV-Infektion sollten daher möglichst im Rahmen von Studien behandelt werden (Information: http://www.hivakut.de).

\section{Therapieoptionen}

Seit der Einführung von Zidovudin als erstem antiretroviralem Medikament im Jahre 1987 wurden über 20 weitere Substanzen mit unterschiedlichen Angriffspunkten entwickelt (Abb.2), so dass heute ein breites Spektrum an Möglichkeiten für Primärtherapie, Salvagetherapie und Postexpositionsprophylaxe zur Verfügung steht. Als Standardregime in der Primärtherapie gelten eine 


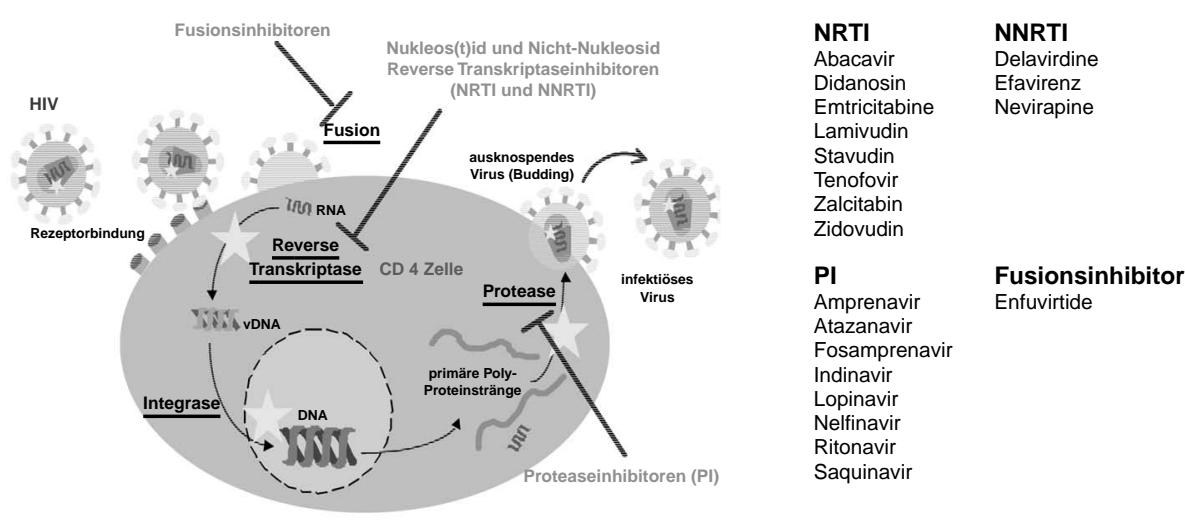

Abb. 2 Replikationszyklus von HIV und bisher verfügbare Medikamentengruppen: Nukleosidische und Nukleotidische Reverse Transkriptaseinhibitoren (NRTI). Wirkmechanismus: Intrazelluläre Phosphorylierung zu Triphosphat, konkurrieren mit den Nukleotiden um die Bindung an die Reverse Transkriptase und führen dort zum Kettenabbruch.

Nicht-Nukleosid Reverse Transkriptaseinhibitoren (NNRTI). Wirkmechanismus: Hemmen die Reverse Transkriptase durch nicht-kompetitive Bindung.

Protease Inhibitoren (PI): Wirkmechanismus: Hemmen die HIV-Protease und inhibieren die Auftrennung der primären Polypeptide und Ausknospung (Budding) aus der Zelle. Fusionsinhibitoren. Wirkmechanismus: Hemmen als synthetische Peptide die Fusion von HIV-1 mit CD4+-Zellen durch Anlagerung an die gp41-Untereinheit der Virusoberfläche.

Kombination von zwei Nukleosid Reverse Transkriptase Inhibitoren (NRTI) in Kombination mit einem Nicht-Nukleosid Reverse Transkriptase Inhibitor (NNRTI) oder die Kombination von zwei NRTI mit einem Ritonavir „geboosterten“ Proteaseinhibitor (PI) [15]. Bei dem „Boostern“ von PI mit einer „Babydose“ Ritonavir von $100-200 \mathrm{mg} / \mathrm{d}$ werden durch die Inhibition des Isoenzyms 3A4 des P450-Enzymsystems die Spiegel fast aller PIs deutlich gesteigert, was zu einer Reduktion der Tablettenanzahl und der Einnahmefrequenz, aber auch zu möglichen Interaktionen mit anderen Medikamenten wie z.B. Rifampicin führt (s.u). Ein Anstieg von > 50 CD4+-Zellen/ $\mu$ l nach 4-8 Wochen spricht für ein gutes immunologisches Ansprechen. Von einem virologischen Therapieerfolg spricht man bei einem Abfall der Viruslast im Plasma unter die Nachweisgrenze von 50 Kopien/ml, dieser Abfall sollte nach 3-4 Monaten, bei initial sehr hoher Viruslast nach 4-5 Monaten erreicht werden. Dem liegt die Erkenntnis zugrunde, dass eine Therapie umso dauerhafter wirkt, je schneller und vor allem je tiefer die Viruslast abfällt [16].

\section{Unerwünschte Wirkungen der antiretroviralen Therapie}

Umstellungen der antiretroviralen Therapie aufgrund von $\mathrm{Ne}$ benwirkungen oder Langzeittoxizitäten sind häufig erforderlich. In einer englischen Kohorte hatten nach 14 Monaten bereits 44\% der Patienten ihr Regime umgestellt [17]. Intoleranzen können meist durch Ersatz eines Medikamentes aus der gleichen Medikamentengruppe behoben werden. Beispiele schwerwiegender Nebenwirkungen sind die Anämie unter Zidovudin, die AbacavirHypersensitivität, die Hepatotoxizität unter Nevirapin, die Nephrolithiasis unter Indinavir, eine periphere Polyneuropathie unter Stavudin, Didanosin, Zalcitabin und die akute Tubulusnekrose unter Tenofovir [18]. Ein häufiges Problem ist das HIV-assoziierte Lipodystrophie-Syndrom. Es ist gekennzeichnet durch klinische und metabolische Veränderungen, die Pathogenese ist komplex (HIV, ART, Genetik). Die Patienten haben typischerweise einen Verlust des peripheren Fettes bei zentraler Adipositas mit zum Teil ungewöhnlicher Fettakkumulation („buffalo hump“). Gleichzeitig besteht in unterschiedlichem Ausmaß eine Fettstoffwechselstörung, eine Glukoseintoleranz und eine Hyperlaktatämie. Eine kürzlich erschienene Studie zeigt ein erhöhtes Risiko unter ART einen Myokardinfarkt zu erleiden [19]. Ein potenziell erhöh- tes kardiovaskuläres Risiko muss aber in jedem Fall in Relation zu der eindeutig reduzierten Mortalität unter der ART bewertet werden.

\section{Resistenzentwicklung}

Ein zentrales Problem der antiretroviralen Therapie besteht in der Bildung von Resistenzen des HI-Virus gegenüber Medikamenten. Als wesentlicher Risikofaktor ist eine unzureichende Virussuppression anzusehen. Virusreplikation in Anwesenheit eines Medikamentes führt zur Selektion von resistenten Virusmutanten. Eine einzelne Punktmutation kann zu hochgradigen Kreuzresistenzen führen, so bewirkt die Mutation K103N einen 20-30fachen Resistenzanstieg gegenüber allen verfügbaren NNRTIs [20]. Die Folge ist ein virologisches Versagen mit einem dauerhaften Virusanstieg auf über $400 \mathrm{Kopien} / \mathrm{ml}$, meist verbunden mit einem Abfall der CD4+ T-Lymphozyten. Die wichtigsten Risikofaktoren für eine Resistenzentwicklung sind eine suboptimale Vorbehandlung (Mono oder Dualtherapie) und eine unregelmäßige oder unvollständige Medikamenteneinnahme [21]. In einer Studie hatten Patienten, die nur 80-94\% der Medikamentendosis eingenommen hatten, in $61 \%$ ein Therapieversagen. Bei einer Compliance von 95\% lag die Rate des Therapieversagens nur bei $22 \%$ [22]. Den Patienten sollten daher die Grundzüge der Resistenzentwicklung erklärt werden. Die Messung der Medikamentenspiegel von PI und NNRTI sind ein zusätzliches Hilfsmittel für die Therapieeinstellung und Therapieüberwachung. Bei virologischem Versagen sollte vor Umstellung der Therapie eine Resistenztestung durchgeführt und nach Umstellung eine Spiegelmessung durchgeführt werden [23]. Mit Hilfe des Resistenzergebnisses und der Medikamentenanamnese kann eine Salvagetherapie mit möglichst vielen neuen Medikamenten begonnen werden. Generell sind die Ansprechraten der Salvagetherapie niedriger als die der Primärtherapie.

Eine Eradikation des Virus gelingt mit den derzeit zur Verfügung stehenden Substanzen nicht. Das Risiko für einen viralen Rebound lag in einer Studie nach 3,3 Jahren bei 25,3\%. Ein echtes virologisches Versagen sah man jedoch nur bei 5,2\% der Patienten, die übrigen Patienten hatten die Therapie aus anderen Gründen unterbrochen [24]. Die Viruslast kann also bei vielen Patien- 
ten jahrelang unter der Nachweisgrenze bleiben. Die Mortalität und Morbidität sinken jedoch auch, wenn die Viruslast nicht unter die Nachweisgrenze abfällt [25]. Insgesamt ist die Mortalitätsrate der HIV-Infektion in Europa durch die ART von 15,6 im Jahr 1994 auf 2,7 pro 100 Patientenjahre (2002) gefallen [26]. Die Kombinationstherapien kosten zwar zwischen 1200 und 2000 Euro pro Monat, teure Behandlungen opportunistischer Infektionen, Krankenhauskosten und Pflegekosten können jedoch eingespart werden. In einer deutschen Studie sanken die jährlichen Kosten von 1997-2001 von 35865 auf 24482 Euro [27]. Viele Patienten werden wieder arbeitsfähig, so dass die ART insgesamt als kosteneffektiv eingestuft werden kann [28].

\section{HIV-assoziierte pulmonale Erkrankungen und opportunistische Infektionen}

Die Atemwege stellen eine der Haupteintrittspforten für Infektionen bei Patienten mit HIV-Infektion dar. Wie wir inzwischen gelernt haben, gibt es daneben auch eine breite Palette nichtinfektiöser Krankheitsmanifestationen (Tab.1). Der Pneumologe kann also auf sehr verschiedene Weise mit dieser Erkrankung konfrontiert werden, und die Möglichkeit einer HIV-Infektion sollte differenzialdiagnostisch immer dann präsent sein, wenn Lebensstil oder ein unklares Krankheitsbild dies möglich erscheinen lassen. Hierbei ist zu berücksichtigen, dass klassische Syndrome wie die interstitielle Pneumonie bei PCP oder das Lungeninfiltrat mit Hautmanifestation beim Kaposi-Sarkom infolge der inzwischen sehr effektiven ART und der Chemoprophylaxe wichtiger opportunistischer Infektionen relativ seltener geworden sind, während die Bedeutung weniger geläufiger Komplikationen zunimmt.

Das Risiko, an definierten Infektionen zu erkranken, lässt sich anhand der absoluten Zahl der CD4+ T-Lymphozyten im Blut grob abschätzen, wobei im Einzelfall mit Abweichungen zu rechnen ist (Abb. 3). Während bakterielle Pneumonien und Tuberkulosen in allen Krankheitsstadien vorkommen, steigt das Risiko, an einer PCP zu erkranken, bei Patienten mit fortgeschrittener Im-

Tab. 1 Pulmonale Komplikationen bei Patienten mit HIV-Infektion

\begin{tabular}{ll}
\hline Infektionen & Nichtinfektiöse Erkrankungen \\
\hline Pneumocystis jiroveci & $\begin{array}{l}\text { Kaposi-Sarkom } \\
\text { Non-Hodgkin-Lymphom } \\
\text { Bakterien }\end{array}$ \\
$\begin{array}{l}\text { Hodgkin-Lymphom } \\
\text { S. aureumoniae }\end{array}$ & $\begin{array}{l}\text { Bronchialkarzinom } \\
\text { lymphozytäre interstitielle Pneumonie }\end{array}$ \\
H. influenzae & unspezifische interstitielle Pneumonie (NSIP) \\
B. catarrhalis & pulmonale Hypertonie \\
P. aeruginosa & \\
Rhodococcus equi & \\
Nocardia asteroides & \\
Mykobakterien & \\
- davon M. tuberculosis & \\
- M. avium intracellulare & \\
Cytomegalovirus & \\
Aspergillus spp. & \\
Cryptococcus neoformans & \\
Histoplasma capsulatum & \\
Toxoplasma gondii & \\
\hline
\end{tabular}

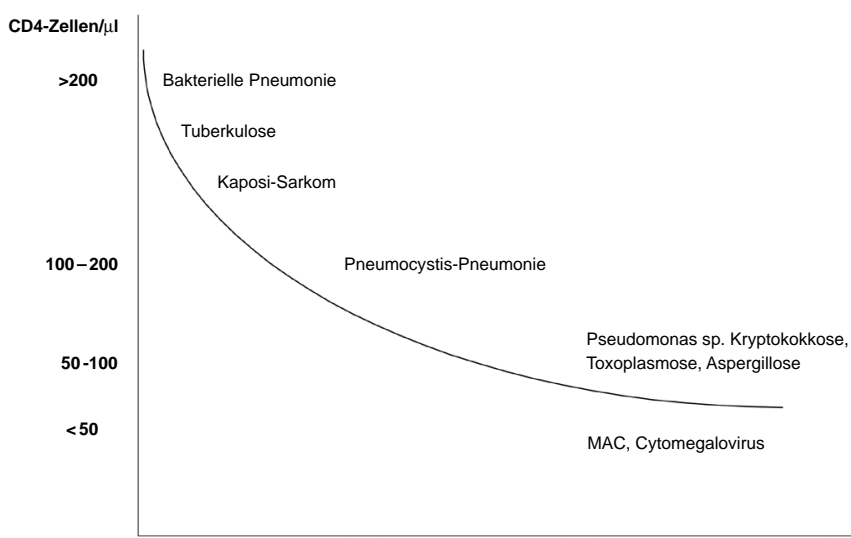

Abb. 3 Auftreten opportunistischer Infektionen im Verlauf der HIV-Infektion.

mundefizienz $(<200-250$ CD4+-Zellen/ $\mu$ l) massiv an. Infektionen durch Cytomegalovirus (CMV) und Mycobacterium avium/ intrazellulare Komplex (MAC) manifestieren sich gehäuft ab CD4-Zellzahlen unter 50/ $\mu 1$ [29]. Unter ART besteht heute die Möglichkeit einer partiellen Immunrekonstitution, so dass sich das Risiko für das Auftreten opportunistischer Infektionen dann deutlich verringert, wenn bei Patienten im Stadium AIDS die CD4+-Zellen unter Therapie für einen Zeitraum von etwa drei Monaten über definierte Grenzwerte angestiegen sind [30]. Andererseits werden unter Immunrekonstitution auch akute Exazerbationen von Infektionen wie Tuberkulose, PCP und CMV beobachtet, die durch den raschen Einstrom immunkompetenter Zellen in die Lunge zu erklären sind und nicht primär als Versagen der antimikrobiellen Therapie zu werten sind [31]. Insgesamt ist die Inzidenz wichtiger pulmonaler Infektionen seit Einführung von ART in den industrialisierten Ländern deutlich gesunken [32]. Darüber hinaus ist die relative Häufigkeit der PCP, die zu Beginn der HIV-Epidemie die häufigste pulmonale Infektion darstellte, in Deutschland zwischen 1987 und 1998 von 58\% auf $46 \%$ der AIDS definierenden Erkrankungen zurückgegangen [33], während der Anteil der bakteriellen Infektionen zunimmt: diese stehen inzwischen in vielen Studien an erster Stelle [32]. Im Folgenden soll wegen der besonderen Bedeutung dieser Infektionen für den Pneumologen schwerpunktmäßig auf bakterielle Pneumonien, Tuberkulose und PCP eingegangen werden.

\section{Bakterielle Pneumonien}

Bakterielle Pneumonien unterscheiden sich bei HIV-infizierten Patienten klinisch und prognostisch nicht signifikant von Infektionen beim immunkompetenten Wirt. Allerdings liegt häufiger ein symptomarmer Verlauf und eine normale Leukozytenzahl vor [34]. Polymikrobielle Infektionen und Koinfektionen mit Pneumocystis jiroveci sind mit $10-30 \%$ häufig, was die klinische Beurteilung erschwert [35-38]. Ätiologisch sind Pneumokokken- und Hämophilusinfektionen am häufigsten. Daneben werden im Vergleich zu immunkompetenten Patienten gehäuft Infektionen mit Staphylococcus aureus, Branhamella catarrhalis sowie in Spätstadien (CD4+ T-Lymphozyten < 100/ $\mu$ l) Pseudomonas spp. gefunden. Bei langsam wachsenden, einschmelzenden Infiltraten ist auch an seltene Erreger wie Rhodococcus equi und 
Nokardien zu denken. Die Basisdiagnostik sollte die Abnahme von zwei Blutkulturen und eine mikroskopische und kulturelle Sputumuntersuchung umfassen. Die Bakteriämierate liegt mit $25-60 \%$ höher als bei immunkompetenten Patienten $[38,40]$. Der Wert der Sputumdiagnostik, die hinsichtlich des Nachweises pyogener Bakterien bei HIV-Infektion unzureichend untersucht ist, liegt vor allem in der Abgrenzung von Mykobakterien- und Aspergillusinfektionen. Die Bestimmung des Kryptokokken-Antigens im Serum hat einen hohen prädiktiven Wert für den Nachweis der invasiven Kryptokokkose [41]. Die Sensitivität der BAL, deren Domäne die PCP-Diagnostik ist, liegt bei bakteriellen Pneumonien nicht vorbehandelter Patienten zwischen $60-70 \%$ $[36,37]$.

Therapeutisch ist bei Patienten mit CD4-Zellzahlen > 200/ $\mu$, falls kein Verdacht auf eine Mykobakteriose besteht, eine kalkulierte antibakterielle Behandlung mit Wirksamkeit gegenüber S. pneumoniae, H. influenzae und S. aureus indiziert. Kontrollierte Studien liegen hierzu nicht vor. In Anlehnung an Therapieempfehlungen zur ambulant erworbenen Pneumonie mit Komorbidität kann die Gabe eines Cephalosporins der Gruppe 2 wie Cefuroxim oder 3a wie Cefotaxim oder Ceftriaxon bzw. eines Aminopenicillins mit Betalaktamaseinhibitor (Ampicillin/sulbactan oder Amoxicillin/Clavulansäure) empfohlen werden. Die Kombination mit einem Makrolid ist bei regional erhöhter Inzidenz von Legionelleninfektionen empfehlenswert. Nach Erhalt positiver Kulturergebnisse sollte gezielt weiter behandelt werden. Bei fortgeschrittenem Immundefizit (CD4+-Zellen <200/ul) sollte wegen des breiteren Erregerspektrums primär eine bronchoskopische Diagnostik erwogen werden $[42,43]$.

\section{Tuberkulose}

Tuberkulose ist die opportunistische Infektion, die weltweit die höchste Morbidität und Mortalität HIV-infizierter Personen bedingt [44]. Etwa ein Drittel der aktuell über 40 Millionen Menschen, die mit einer HIV-Infektion leben, sind mit Mycobacterium tuberculosis Komplex (Mycobacterium tuberculosis, M. africanum, M. bovis oder M. microtii-MTB) koinfiziert, 70\% der Betroffenen leben im zentralen und südlichen Afrika [45]. Während in Deutschland die Inzidenzen für Tuberkulose und HIV in den vergangenen Jahren auf niedrigem Niveau stagnieren $[46,47]$, ist die deutliche Zunahme von Tuberkuloseerkrankungen in den meisten Regionen der Welt während der letzten zwei Jahrzehnte eng mit der HIV-Epidemie verbunden [48]. So sind in einigen Ländern des südlichen Afrikas bis zu 70\% der Tuberkulosekranken gleichzeitig mit HIV infiziert [49].

Einerseits ist die Anzahl postprimärer Tuberkuloseerkrankungen und die der Reaktivierungen einer latenten Infektion mit MTB bei HIV-infizierten Personen gegenüber HIV-seronegativen Personen deutlich erhöht [50], andererseits führt auch die Tuberkulose zu einem Progress der Immundefizienz bei den HIV-infizierten Personen [51]. Während die meisten opportunistischen Infektionen nur im fortgeschrittenen Stadium der HIV-Infektion auftreten, können HIV-Infizierte daher unabhängig von der Anzahl zirkulierender CD4+ T-Lymphozyten in allen Stadien der Infektion an einer Tuberkulose erkranken [52]. Über 50\% der Tuberkulosefälle treten bei Patienten mit CD4+ T-Lymphozyten-
Konzentrationen von > 200 Zellen/ $\mu$ im zirkulierenden Blut auf. Die Inzidenz der Tuberkulose steigt aber mit fortgeschrittenem Immundefekt bei der HIV-Infektion und ist im Stadium AIDS am höchsten [53].

\section{TB: Einfluss auf die HIV-Infektion}

Eine aktive Tuberkuloseerkrankung führt bei HIV-infizierten Patienten zunächst lokal zu einer Aktivierung der HIV-Replikation und sekundär auch zu einer höheren HIV-RNA-Konzentration im zirkulierenden Blut [54]. Dieser Effekt ist in frühen Stadien der HIV-Infektion besonders ausgeprägt [54]. Die Zunahme der Plasmavirämie ist einer der bedeutendsten Risikofaktoren für die Progression der Immundefizienz zum Stadium AIDS [55]. Sowohl in der bronchoalveolären Lavage wie auch im Pleuraerguss tuberkulosekranker HIV-koinfizierter Patienten werden signifikant höhere HIV-RNA-Konzentrationen gefunden, als bei Tuberkulose-negativen Kontrollen [56]. Die Pathogenese der Aktivierung der HIV-Replikation durch MTB ist sehr komplex und wird bislang nur unvollständig verstanden. Neben einer gesteigerten Replikation von HIV in aktivierten, HLA-DR+-Makrophagen [51] und einer Reaktivierung latent HIV-infizierter Monozyten [57] spielen proinflammatorische Zytokine v.a. TNF $\alpha$, IL 1 $\beta$, MCP1 und der nukleäre Faktor Kappa-B eine bedeutende Rolle bei der Aktivierung der HIV-Replikation [51].

\section{HIV: Einfluss auf die Tuberkulose}

Die Pathogenese der Tuberkulose hängt vom Stadium der Immundefizienz bei der HIV-Infektion ab. Oft handelt es sich bei Patienten in frühen Stadien (> 500 CD4+ T-Lymphozyten/ $\mu$ l) der Erkrankung um Reaktivierungen latenter MTB-Infektionen, während Patienten mit fortgeschrittener Immundefizienz häufig Anzeichen einer progressiven postprimären Tuberkulose aufweisen [58]. Bei diesen Patienten ist die Formation von Granulomen durch den Verlust von CD4+ T-Lymphozyten gering [59] und es treten häufig miliare Streuungen durch hämatogene und lymphatische Aussaat der Bakterien auf [60].

\section{Latente Infektion mit MTB}

Nur 5-10\% der HIV-seronegativen, aber ca. 50\% der HIV-seropositiven Patienten, die latent mit MTB infiziert sind, entwickeln im weiteren Verlauf eine Tuberkuloseerkrankung [61]. Der Tuberkulin-Hauttest nach Mendel-Mantoux gilt bislang als Goldstandard für die Diagnose einer latenten Tuberkulose. Aufgrund des T-ZellImmundefekts fällt die Induration beim Tuberkulin-Hauttest bei HIV-infizierten Patienten jedoch nur gering aus. Eine Induration $\geq 5 \mathrm{~mm}$ gilt bereits als positive Reaktion für HIV-seropositive Personen [62]. Bei Patienten in fortgeschrittenen Stadien der HIV-Infektion fällt das Testergebnis dennoch in den meisten Fällen falsch negativ aus [63]. Ein negatives Testergebnis beim Mendel-Mantoux-Test als Ausdruck einer Anergie ist bei HIV/TB koinfizierten Patienten ein prognostischer Marker, der mit hoher Mortalität assoziiert ist [64].

\section{Klinische Verlaufsformen der Tuberkulose}

Bei den Reaktivierungen latenter Tuberkuloseinfektionen in frühen Stadien der HIV-Infektion handelt es sich in der Regel um klassische pulmonale Verlaufsformen mit infiltrativen, Oberlappen-betonten Beherdungen mit Hohlraumbildungen analog zum Krankheitsbild bei HIV-seronegativen Patienten (Abb.4). Im Sputum lassen sich meistens säurefeste Stäbchen darstellen. 
Mit fortschreitender Immundefizienz treten vermehrt atypische pulmonale Verlaufsformen ohne Kavernenbildung mit ausgeprägter mediastinaler Lymphadenopathie sowie extrapulmonale Verlaufsformen auf. In der Sputumanalyse sind dann häufig keine säurefesten Stäbchen nachweisbar [65]. Im Vergleich zu HIVseronegativen Patienten ist das Übertragungsrisiko von MTB durch HIV-seropositive Patienten daher geringer [66]. Bei etwa $5 \%$ der Patienten, bei denen sich keine Infiltrate im Röntgen-Thorax-Bild darstellen, fällt die mikroskopische Sputumanalyse positiv aus [52] und im Einzelfall kann eine hohe Anzahl von Mykobakterien im Sputum nachgewiesen werden. Außerdem gibt es Hinweise dafür, dass das Risiko für die Übertragung multiresistenter Tuberkulosebakterien bei HIV-infizierten Patienten gesteigert ist [67]. Daher sollten die Standardmaßnahmen zur Transmissionsprophylaxe unbedingt eingehalten werden [68].

\section{Diagnose}

Die Stufendiagnostik unterscheidet sich bei HIV-seropositiven Patienten nicht vom üblichen Vorgehen bei der Tuberkulose. Aus Sputen und anderen biologischen Materialien werden die Präparate zunächst auf das Vorkommen säurefester Stäbchen hin untersucht. Inzwischen stehen auch verschiedene rasch durchführbare und empfindliche Verfahren zum Nachweis von MTB-spezifischen Gensequenzen zur Verfügung. Mit Verfahren zur Nukleinsäureamplifikation (z.B. Polymerase-Ketten-Reaktion; PCR) können in Sputumpräparaten, in denen mikroskopisch säurefeste Stäbchen beobachtet wurden, Tuberkulosebakterien mit einer Sensitivität von $>95 \%$ nachgewiesen werden. In den mikroskopisch negativen Präparaten fällt die Sensitivität der PCR-Untersuchung aber auf $40-77 \%$ ab [69]. Da Tuberkulosebakterien mikroskopisch nicht von anderen säurefesten Stäbchen unterschieden werden können, eignet sich die PCR zu einer raschen Differenzierung vor allem gegenüber nicht-tuberkulösen Mykobakterien.

In der Diagnose einer Tuberkulose ist bronchoskopisch gewonnenes Bronchialsekret induziertem Sputum bei HIV-infizierten Personen nicht überlegen [70]. Bei ZN-negativen Befunden ist die Bronchoskopie aber zur Differenzierung gegenüber anderen Erkrankungen meistens unerlässlich [71], außerdem kann die histologische Bewertung von transbronchialen Biopsien dazu beitragen, die Diagnose einer Tuberkulose durch den Nachweis von Granulomen oder säurefester Stäbchen zu erhärten. Der Goldstandard ist unverändert der kulturelle Nachweis von Tuberkulosebakterien in Flüssig- (ca. 2-4 Wochen) oder Festmedien (ca. 3-5 Wochen). Eine Resistenztestung ist bei kulturellem Nachweis von MTB immer erforderlich.

Der Hauttest nach Mendel-Mantoux ist aufgrund der hohen Rate falsch negativer Befunde bei HIV-infizierten Patienten diagnostisch nur eingeschränkt verwertbar. Neuere Verfahren zur Bestätigung einer stattgehabten MTB-Sensibilisierung durch den Nachweis tuberkulose-spezifischer T-Lymphozyten in biologischen Präparaten, z.B. ein ELISPOT zum Nachweis einer $\gamma$-Interferon-Sekretion nach Kontakt mit dem Antigen ESAT-6, sind in experimenteller Erprobung.

\section{Therapie}

Mit einer Standardtherapie der Tuberkulose kann unabhängig vom Status einer antiretroviralen Therapie (ART) bei HIV/TBC koinfizierten Patienten in gleicher Zeit eine Sputumkonversion und ein vergleichbarer Behandlungserfolg erzielt werden, wie bei HIV-seronegativen Personen [72,73]. In unkomplizierten Fällen ist daher für die Therapie der pulmonalen Tuberkulose auch bei HIV-koinfizierten Patienten eine Behandlungsdauer der Tuberkulose von 6 Monaten ausreichend [74]. Die synchrone Behandlung der HIV-Infektion mit einer antiretroviralen Therapie und der Tuberkulose mit Antituberkulotika ist aber in der Praxis problematisch. So traten nach Einleitung einer antituberkulösen Behandlung bei 7\% der ART-naiven Patienten paradoxe Reaktionen mit Fieber, Lymphadenopathie und neuen pulmonalen Infiltraten auf. Bei Patienten, die gleichzeitig mit einer ART behandelt wurden traten diese Immunrekonstitutionsphänomene deutlich öfter, nämlich in 36\% der Fälle auf [75]. Daneben erschweren Complianceprobleme durch die hohe Anzahl an Tabletten (i.d.R. mind. 3 Präparate zur HIV-Therapie und initial 4 Präparate zur Behandlung der Tuberkulose) und Arzneimittelinteraktionen die gleichzeitige Therapie der HIV- und MTB-Infektion nicht unerheblich. Beispielsweise werden sowohl Rifampicin als auch Proteaseinhibitoren (PI) über das Enzym Cytochrom $\mathrm{P}_{450}$ metabolisiert. Da die Medikamentenspiegel deshalb nicht kalkulierbar sind, wird eine gleichzeitige Behandlung von Rifampicin
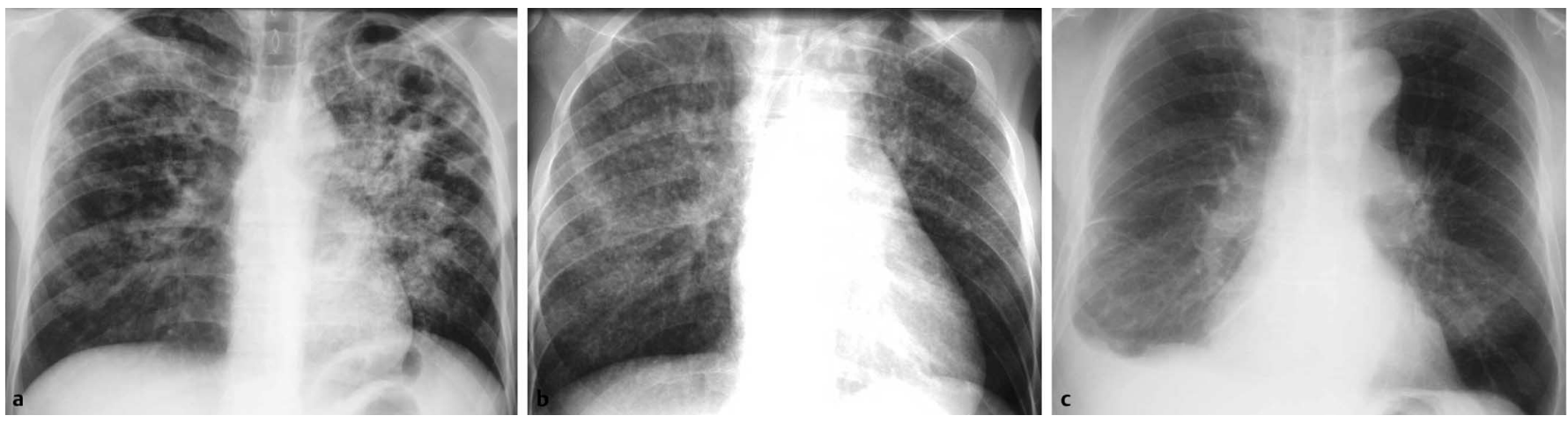

Abb. 4 Repräsentative Röntgenaufnahmen des Thorax bei Patienten mit HIV-Infektion und Tuberkulose. In frühen Stadien der HIV-Infektion entsprechen die radiologischen Veränderungen der Lungentuberkulose meistens den klassischen Bildern HIV-seronegativer Patienten, während bei fortgeschrittener Immundefizienz vermehrt miliare, atypische und extrapulmonale Verlaufsformen auftreten. Patient A: 35 j. Mann mit kavernöser Tuberkulose und multiplen infiltrativen Herdsetzungen; 510 CD4+ T-Zellen/ $\mu \mathrm{L}$ (23\%). Patientin B: 28 j. Frau mit Miliartuberkulose; 193 CD4+ T-Zellen/ $\mu \mathrm{L}$ (18\%). Patient C: Progressive postprimäre Tuberkulose mit tuberkulöser Pleuritis. 35 CD4+ T-Zellen/ $\mu \mathrm{L}$ (8\%). Bei Patient A mikroskopischer Nachweis säurefester Stäbchen im Sputum. Bei allen drei Patienten kultureller Nachweis von MTB im Sputum. 
und PIs (Ausnahmen: Ritonavir \pm Saquinavir; neuerdings auch Ritonavir hypergeboostertes Lopinavir) nicht empfohlen (Tab. 2) [76]. Für die gleichzeitige Behandlung der HIV-Infektion steht damit nur eine Kombination aus 2 Nukleosidalen-Reverse-Transkriptase-Inhibitoren (NRTI) mit dem Nicht-Nukleosidalen-Reverse-Transkriptase-Inhibitor (NNRTI) Efavirenz oder die suboptimale Kombination aus 3 NRTIs zur Verfügung. Alternativ zu Rifampicin kann Rifabutin als schwächerer Induktor des Cytochrom $\mathrm{P}_{450}$ auch in Kombination mit PIs verwendet werden. Wird kombiniert therapiert, müssen Dosisanpassungen der Medikamente beachtet und NNRTI bzw. PI-Spiegelmessungen durchgeführt werden [77] (Tab. 2).

Wegen dieser Probleme sollte, wenn es der Immunstatus der Patienten erlaubt, eine parallele Therapie der HIV- und MTB-Infektion vermieden werden [78]. Bei HIV-infizierten Patienten mit stark fortgeschrittener Immundefizienz und < 100 CD4+ T-Lymphozyten/ $\mu \mathrm{L}$ muss aber bei Auftreten einer Tuberkulose aufgrund des hohen Mortalitätsrisikos eine parallele Behandlung dringend erwogen werden [79]. Gegebenenfalls kann bei therapienaiven Patienten auch dann mit der Einleitung einer ART bis zum Abschluss der 2-monatigen Induktionsphase der Tuberkulosetherapie abgewartet werden. Bei Patienten mit 100-200 $\mathrm{CD} 4+Z e l l e n / \mu l$ sollte mindestens zwei Monate, ggf. auch länger mit dem Beginn einer antiretroviralen Therapie abgewartet werden. Bei Patienten mit mehr als 200 CD4+-Zellen/ $\mu$ l sollte die
Antituberkulöse-Therapie vor Einleitung einer ART abgeschlossen sein. Die Therapie kann dann nach den gleichen Prinzipien, wie für die Behandlung HIV-seronegativer Personen durchgeführt werden (6-9 Monate Isoniazid und Rifampicin, initial 2 Monate Ethambutol und Pyrazinamid oder - alternativ zu EMB oder PZA-Streptomycin [80]). HIV-infizierten Patienten, die bereits mit einer ART behandelt werden und an einer Tuberkulose erkranken, wird empfohlen die ART fortzusetzen. Eventuell muss die ART aber im Hinblick auf die synchrone Therapie der Tuberkulose umgestellt werden [79].

Bei Nachweis multiresistenter Mykobakterien, definiert durch eine Resistenz gegenüber INH und Rifampicin, ist die Therapie weiter erschwert [81]. Der Therapieerfolg ist geringer und die Behandlungsdauer länger als bei sensiblen Tuberkulosestämmen. Aufgrund der Komplexität der Therapie sollten Patienten, die an einer Tuberkulose bei einer HIV-Infektion erkranken, in dafür spezialisierten Zentren behandelt werden.

HIV-infizierte Personen mit positivem Mendel-Mantoux-Test haben ein 5 - 10fach erhöhtes Risiko, an einer aktiven Tuberkulose zu erkranken. Die Effektivität einer INH-Monotherapie zur Vermeidung der Entwicklung einer Tuberkuloseerkrankung wurde für diese Patienten auch ohne ART in zahlreichen Studien belegt [82]. ART-naive Patienten mit negativem Mendel-Mantoux-Test profitieren hingegen weder von einer Therapie der latenten Tu-

Tab. 2 Dosisanpassung bei synchroner Behandlung mit antiretroviralen Medikamenten und Rifampicin und Rifabutin (nach [50])

\begin{tabular}{|c|c|c|}
\hline & Dosisanpassung der antiretroviralen Medikamente & Rifampicin Dosis \\
\hline Amprenavir & sollten nicht gemeinsam gegeben werden & \\
\hline Atazanavir & sollten nicht gemeinsam gegeben werden & \\
\hline Indinavir & sollten nicht gemeinsam gegeben werden & \\
\hline Nelfinavir & sollten nicht gemeinsam gegeben werden & \\
\hline Lopinavir/Ritonavir & $\begin{array}{l}\text { Lopinavir } 400 \mathrm{mg} / 12 \mathrm{~h} \text { und Ritonavir } 100 \mathrm{mg} / 12 \mathrm{~h} \\
\text { plus weitere Ritonavir } 300 \mathrm{mg} / 12 \mathrm{~h}\end{array}$ & $600 \mathrm{mg} / \mathrm{d}$ \\
\hline Saquinavir/ Ritonavir & Saquinavir $400 \mathrm{mg} / 12 \mathrm{~h}$ und Ritonavir $400 \mathrm{mg} / 12 \mathrm{~h}$ & $600 \mathrm{mg} / \mathrm{d}$ \\
\hline Efavirenz & $\uparrow 800 \mathrm{mg} / \mathrm{d}$ & $600 \mathrm{mg} / \mathrm{d}$ \\
\hline Nevirapin & $200 \mathrm{mg} / 12 \mathrm{~h}$ & $600 \mathrm{mg} / \mathrm{d}$ \\
\hline Fos- Amprenavir & keine & $\downarrow 150 \mathrm{mg} / \mathrm{d}$ oder $300 \mathrm{mg} 3 \times /$ Woche \\
\hline Atazanavir & keine & $\downarrow 150 \mathrm{mg} / 2 \mathrm{~d}$ oder $150 \mathrm{mg} 3 \times /$ Woche \\
\hline Indinavir & $\uparrow 1000 \mathrm{mg}$ alle $8 \mathrm{~h}$ & $\downarrow 150 \mathrm{mg} / \mathrm{d}$ oder $300 \mathrm{mg} 3 \times /$ Woche \\
\hline Nelfinavir & $\uparrow 1000 \mathrm{mg}$ alle $8 \mathrm{~h}$ & $\downarrow 150 \mathrm{mg} / \mathrm{d}$ oder $300 \mathrm{mg} 3 \times /$ Woche \\
\hline Ritonavir & keine & $\downarrow 150 \mathrm{mg} / 2 \mathrm{~d}$ oder $150 \mathrm{mg} 3 \times /$ Woche \\
\hline Saquinavir & sollten nicht gemeinsam gegeben werden & \\
\hline Lopinavir/Ritonavir & keine & $\downarrow 150 \mathrm{mg} / 2 \mathrm{~d}$ oder $150 \mathrm{mg} 3 \times /$ Woche \\
\hline $\begin{array}{l}\text { Ritonavir und Amprenavir, } \\
\text { Fos-Amprenavir, Atazanavir, Indinavir oder Saquinavir }\end{array}$ & keine & $\downarrow 150 \mathrm{mg} / 2$ d oder $150 \mathrm{mg} 3 \times /$ Woche \\
\hline Efavirenz & keine & $\uparrow 450 \mathrm{mg} / \mathrm{d}$ oder $600 \mathrm{mg} 3 \times /$ Woche \\
\hline Nevirapin & keine & $\uparrow 300 \mathrm{mg} / \mathrm{d}$ oder $300 \mathrm{mg} 3 \times /$ Woche \\
\hline
\end{tabular}


berkulose [82] noch von einer Sekundärprophylaxe [83]. Bei ART-naiven Patienten hat die Chemoprophylaxe bei latenter Tuberkulose auch keinen Einfluss auf die Gesamtmortalität. Wie sich die Prognose HIV-infizierter Patienten mit latenter Tuberkulose unter antiretroviraler Therapie verändert, sollte in prospektiven Studien genauer untersucht werden.

Patienten mit positivem Mendel-Mantoux-Test wird aktuell eine Therapie mit INH (+ Pyridoxin) über neun Monate angeraten. HIV-seropositiven Personen mit negativem Ergebnis im Tuberkulinhauttest und gesicherter kürzlicher Exposition gegenüber Patienten mit offener Lungentuberkulose sollte die gleiche Behandlung angeboten werden [84]. Die zweimonatige Behandlung der latenten Tuberkulose mit Rifampicin und Pyrazinamid kann aufgrund der deutlich erhöhten Toxizität hingegen nicht mehr empfohlen werden [85].

\section{Nicht-tuberkulöse Mykobakterien}

Klinisch manifeste Infektionen mit $\mathrm{M}$. avium intracellulare (MAC) gehörten vor Einführung der ART in den industrialisierten Ländern zu den häufigsten opportunistischen Infektionen bei HIV-Infektion [86]. Im Zeitalter der ART ist die Inzidenz der MAC-Infektion bei HIV-infizierten Patienten dramatisch gesunken und das klinische Spektrum hat sich von einer disseminierten Erkrankung mit Bakteriämie zu einer meist lokalisierten Erkrankung mit Lymphadenopathie oder Osteomyelitis gewandelt [87]. Eine pulmonale MAC-Infektion bei HIV-Infizierten Patienten war früher bereits selten und ist heute eine Rarität. Erkrankungen durch andere nicht-tuberkulösen Mykobakterien, die sich häufiger pulmonal manifestieren, wie z.B. M. kansasii, M. malmoense, M. gordonae, M. xenopi oder M. celatum sind ebenfalls auch bei HIV-infizierten Patienten sehr selten geworden. Sie sind fast ausschließlich bei Therapie-naiven Patienten mit weit fortgeschrittenem Immundefekt ( $<50 \mathrm{CD} 4+\mathrm{T}$-Lymphozyten $/ \mu \mathrm{L}$ ), bei Patienten mit Therapieversagen oder Incompliance, oder als Manifestation eines Immun-Rekonstitutions-Syndrom kurz nach Einleitung einer ART zu beobachten. Das Spektrum mögli-

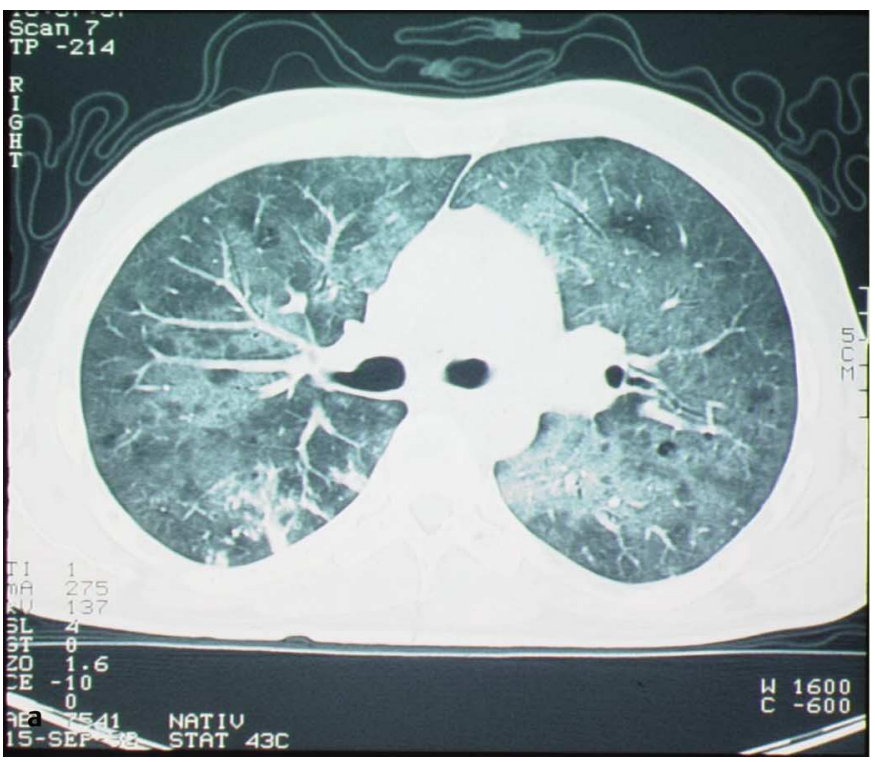

cher radiologischer Veränderungen umfasst flächige/streifige Infiltrate, Noduli, Kavernen und eine Lymphadenopathie [88]. Die Diagnose erfolgt durch den mikroskopischen, molekularbiologischen und kulturellen Nachweis säurefester Stäbchen im Sputum, im Bronchialsekret oder in transbronchialen Biopsien (s. o.). Bezüglich der speziellen Therapieregime wird auf die Literatur verwiesen $[88,89,90]$.

\section{Pneumocystis-Pneumonie (PCP)}

Pneumocystis carinii hat in den letzten Jahren aufgrund neuer taxonomischer Erkenntnisse eine Umbenennung in P. jiroveci (Abkürzung der Infektion weiterhin $\mathrm{PCP}=$ Pneumocystis-Pneumonie) durchgemacht. Es handelt sich entgegen ersten Vermutungen nicht um einen Parasiten, sondern um einen Pilz, der allerdings auf übliche Antimykotika aufgrund besonderer Zellwandstrukturen nicht anspricht. Klinisch ist die PCP im Gegensatz zu bakteriellen Pneumonien meist durch einen subakuten Verlauf mit langsam progredienter Dyspnoe gekennzeichnet. Bei etwa $10 \%$ der betroffenen Patienten fällt die Röntgenuntersuchung normal aus, während die Computertomographie schon früh milchglasartige Verschattungen von landkartenartiger Umgrenzung zeigen kann (Abb. 5). Belastungsuntersuchungen wie die Spiroergometrie ergeben ebenfalls frühzeitig eine eingeschränkte pulmonale Reserve. Die Patienten klagen über trockenen Husten, der Auskultationsbefund ist meist unauffällig. In der Lungenfunktion sind eine respiratorische Partialinsuffizienz mit Diffusionsstörung charakteristisch. Fieber und interstitielle Lungeninfiltrate sind Zeichen eines fortgeschrittenen Krankheitsstadiums. Differenzialdiagnostisch ist in der CT eine Aussparung der subpleuralen Areale charakteristisch. Daneben werden auch fokale Infiltrate mit Bevorzugung der Oberfelder beobachtet, zystische Umwandlungen und Pneumatozelen treten v.a. unter Pentamidinprophylaxe gehäuft auf [91]. Bei derartigen Manifestationen steigt auch das Pneumothoraxrisiko. Pleuraergüsse und hiläre Lymphadenopathien sind dagegen selten, was in der Differenzialdiagnose gegenüber anderen Infektionen verwertet werden kann.

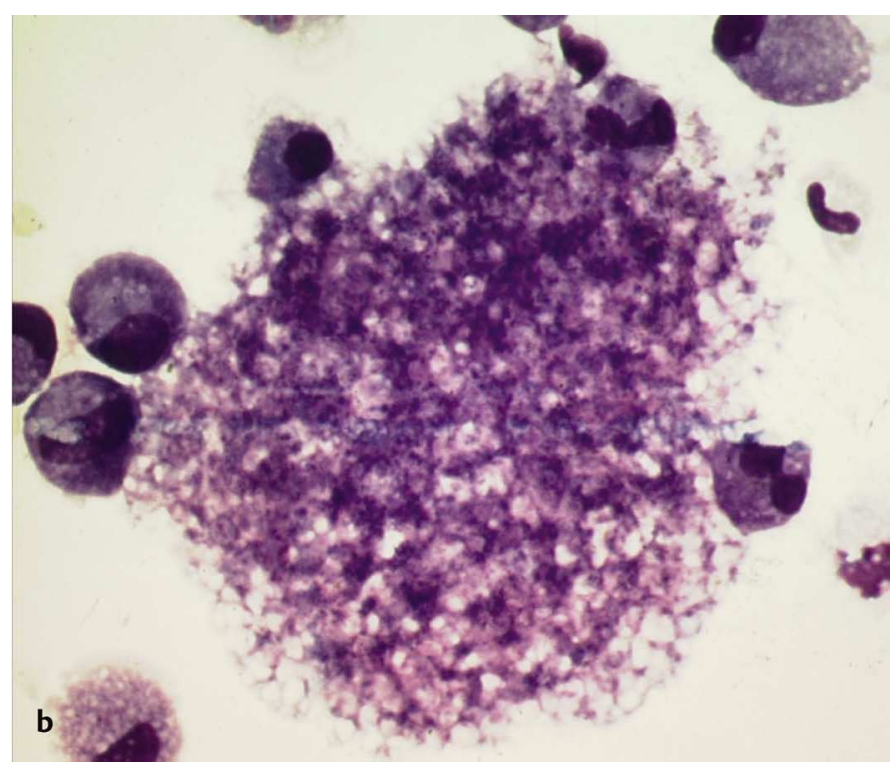

Abb. 5 CT-Befund (a) und MGG-gefärbter BAL-Ausstrich (b) bei Pneumocystis jiroveci-Pneumonie; 32-jähriger HIV-infizierter Patient. 
Bei Verdacht auf PCP ist primär die Durchführung einer bronchoskopischen Diagnostik sinnvoll [36], auch wenn kontrollierte Untersuchungen im Vergleich zu einem nichtinvasiven Vorgehen fehlen. Die Trefferquote der BAL liegt bei nicht vorbehandelten Patienten zwischen $85-100 \%$ und kann durch weitere Maßnahmen kaum gesteigert werden. Daher bietet die primäre Durchführung der transbronchialen Biopsie mit ihrem höheren Komplikationsrisiko bei Verdacht auf PCP keine Vorteile [36]. Bei Patienten unter Chemoprophylaxe gegen P. jiroveci sowie bei negativem Ausfall der Erstdiagnostik ist dagegen mit einer niedrigeren Trefferquote der BAL zu rechnen. In diesen Fällen lässt sich die Sensitivität durch Mehrlappenlavage, insbesondere im Oberlappen, und TBB deutlich steigern $[92,93]$. Der Einsatz der Sputumuntersuchung in der PCP-Diagnostik wird kontrovers diskutiert. In spezialisierten HIV-Zentren hat sich das induzierte Sputum mit einer Sensitivität von $60-70 \%$ als erste diagnostische Methode etabliert [94]. Allerdings liegt der negative Vorhersagewert nur bei $39-64 \%$, so dass bei negativem Befund bronchoskopiert werden muss. Zudem ist die Qualität in hohem Grade untersucherabhängig, und Koinfektionen mit anderen Erregern werden häufig nicht erfasst.

Mittel der Wahl für die Therapie der PCP ist Co-trimoxazol, das in der zur Behandlung der PCP erforderlichen Dosierung eine Reihe bakterieller Erreger ebenfalls gut erfasst. Ersatzweise kommen Pentamidin, Trimethoprim/Dapson und andere Reservesubstanzen in Betracht (Tab. 3). Co-trimoxazol sollte bei fehlenden Kontraindikationen bevorzugt werden, da es in kontrollierten Studien [95] gegenüber Pentamidin eine signifikant höhere Erfolgsrate hinsichtlich des Patientenüberlebens zeigte. Nebenwirkungen wie Allergien, Myelosuppression, daneben auch Hyperkaliämie, Niereninsuffizienz und Hepatotoxizität sind häufig und führen zu einer Abbruchrate von 20 - 57\%. Von einer begleitenden Folinsäuregabe ist abzuraten, nachdem hierunter eine erhöhte Mortalität beobachtet wurde [96]. Die unerwünschten Wirkungen von Pentamidin umfassen Niereninsuffizienz, Leukopenie, akute Pankreatitis, Hypoglykämien und Kardiotoxizität. Inhalatives Pentamidin weist zwar ein günstigeres Nebenwirkungsprofil auf, ist aber in therapeutischer Indikation nicht ausreichend wirksam [97]. Dapson/Trimethoprim erwies sich in einer randomisierten Studie gegenüber Co-trimoxazol bei geringerer Toxizi-

Tab. 3 Therapie der Pneumocystis-Pneumonie bei HIV-Infektion (nach [43])

\begin{tabular}{|c|c|c|c|c|c|}
\hline Verlauf & Substanz & Tagesdosis & $\begin{array}{l}\text { Einzel- } \\
\text { dosen/d }\end{array}$ & $\begin{array}{l}\text { Applika- } \\
\text { tion }\end{array}$ & Dauer (d) \\
\hline leicht & Co-trimoxazol & $90 \mathrm{mg} / \mathrm{kg}$ & $3-4$ & p.o. & 21 \\
\hline \multirow{5}{*}{$\begin{array}{l}\text { mittel- } \\
\text { schwer/ } \\
\text { schwer }\end{array}$} & $\begin{array}{l}\text { Co-trimoxazol } \\
\text { alternativ: }\end{array}$ & $\begin{array}{l}90-120 \\
\mathrm{mg} / \mathrm{kg}\end{array}$ & 4 & \multirow[t]{2}{*}{$\begin{array}{l}\text { i.v./p.o. } \\
\text { i.v. }\end{array}$} & 21 \\
\hline & Pentamidin & $3-4 \mathrm{mg} / \mathrm{kg}$ & 1 & & 21 \\
\hline & Dapson/ & $100 \mathrm{mg}$ & 1 & p.o. & 21 \\
\hline & Trimethoprim & $15 \mathrm{mg} / \mathrm{kg}$ & 3 & p.o. & 21 \\
\hline & Atovaquone & $2250 \mathrm{mg}$ & 3 & p.o. & 21 \\
\hline \multirow[t]{3}{*}{ adjuvant } & Prednison* & $80 \mathrm{mg}$ & 2 & \multirow[t]{3}{*}{ p.o. } & 3 \\
\hline & & $40 \mathrm{mg}$ & 1 & & 3 \\
\hline & & $20 \mathrm{mg}$ & 1 & & 3 \\
\hline
\end{tabular}

* bei $\mathrm{pO}_{2}<70 \mathrm{mmHg}$ in Ruhe tät als gleichwertig. Allerdings muss ein Glukose-6-phosphatdehydrogenasemangel ausgeschlossen werden, weil sonst mit schweren Hämolysen gerechnet werden muss [98]. Bei Vorliegen einer Hypoxämie mit einem $\mathrm{pO}_{2}<70 \mathrm{~mm} \mathrm{Hg}$ ist zusätzlich die Gabe von Glucocorticoiden indiziert. Diese adjuvante Therapie hat in mehreren unkontrollierten und einer kontrollierten Studie [99] bei HIV-infizierten Patienten mit PCP deutliche Vorteile hinsichtlich Morbidität und Mortalität gezeigt. Eine Besserung der klinischen Symptomatik ist unter Therapie der PCP erst nach 3-5 Tagen zu erwarten, so dass eine Beurteilung des Therapieerfolgs erst nach diesem Intervall möglich ist. Zur Therapiedauer existieren keine Daten aus randomisierten Studien. Von den meisten Zentren wird eine Behandlung über 21 Tage empfohlen. Bei Umstellung nach Therapieversagen sollte mindestens zwei weitere Wochen behandelt werden, um Rezidive zu vermeiden.

Eine PCP-Primärprophylaxe zählt zu den wichtigsten Maßnahmen bei fortgeschrittener HIV-Infektion und sollte dann begonnen werden, wenn die Zahl der CD4+ T-Lymphozyten weniger als $250-200 / \mu l$ beträgt. Weitere Indikationen bei ART-naiven Patienten sind der Nachweis einer oropharyngealen Candidose oder AIDS-definierender Erkrankungen. Mittel der Wahl ist auch hier Co-trimoxazol, das in einer Dosierung von $960 \mathrm{mg} / \mathrm{d}$ ( $\cong 1$ Forte-Tablette/d) signifikant wirksamer als Alternativregime wie Dapson oder Pentamidin ist, aber auch in niedrigeren Dosen wie $1 \times 480 \mathrm{mg} / \mathrm{d}$ oder $3 \times 960 \mathrm{mg} /$ Woche effektiv ist $[100,101]$. Die Sekundärprophylaxe nach durchgemachter PCP kann nach denselben Kriterien durchgeführt werden. Bei Kontraindikationen oder Unverträglichkeit kann auf Dapson ausgewichen werden, das trotz seiner Sulfonamidstruktur von der Mehrzahl der Patienten mit Co-trimoxazol-Unverträglichkeit toleriert wird [102]. Eine weitere Alternative stellt inhalatives Pentamidin dar, dessen Vorzug die gute systemische Verträglichkeit ist. Die überlegene Wirkung von Co-trimoxazol gegenüber den Vergleichssubstanzen ist besonders bei hochgradigem Immundefekt mit CD4-Zellzahlen $<100 / \mu l$ von Bedeutung [103]. Ein weiterer Vorteil ist die gleichzeitige Prophylaxe gegen eine Toxoplasmose-Reaktivierung [37]. Steigt unter ART die Zahl der CD4+ T-Lymphozyten stabil auf $>200$ Zellen/ $\mu$ l an, kann die Prophylaxe 3-6 Monate nach Überschreiten des Grenzwertes beendet werden [29].

\section{Weitere opportunistische Infektionen}

Eine klinisch manifeste Cytomegalovirus-Pneumonie wird bei AIDS mit 3,5\% aller infektiösen Lungeninfiltrate im Vergleich zu extrathorakalen Manifestationen selten beobachtet, obwohl die Seroprävalenz mit $>90 \%$ hoch ist und eine Kolonisation der Atemwege häufig gefunden wird. Allerdings wurde histologisch anhand von Autopsiematerial in bis zu $17 \%$ eine pulmonale CMV-Infektion diagnostiziert, so dass die Bedeutung des Erregers in Spätstadien möglicherweise unterschätzt wird [104,105].

Mit einem erhöhten Risiko für invasive pulmonale Aspergillosen (IPA) ist bei HIV-infizierten Patienten nur im Spätstadium bei Vorliegen zusätzlicher Risikofaktoren wie Neutropenie oder Steroidtherapie zu rechnen [106]. Bei Verdacht auf IPA oder CMVInfektion sollte primär eine bronchoskopische Diagnostik mit Kombination von BAL und TBB angestrebt werden, da eine siche- 
re Abgrenzung von Kolonisation und invasiver Infektion nur durch den Nachweis der Gewebsinvasion möglich ist [106]. Bei der Kryptokokkose dienen die Atemwege als Eintrittspforte, während die Prognose durch die zerebrale Manifestation mit aseptischer Meningoenzephalitis beherrscht wird. Hauptmanifestation in der Lunge sind fokale, meist langsam wachsende Konsolidationen. Nach Aufenthalten in außereuropäischen Ländern muss darüber hinaus auch mit Histoplasmosen und anderen endemischen Pilzinfektionen gerechnet werden [107].

\section{Ausblick}

Insgesamt zeigen die großen Fortschritte der ART ebenso wie die Erfolge von stringent durchgeführten Aufklärungs- und Prophylaxeprogrammen, dass die HIV-Infektion heute eine prinzipiell beherrschbare Erkrankung geworden ist. Leider stehen diese Möglichkeiten für die meisten betroffenen Menschen in den wirtschaftlich ärmeren Ländern aktuell nicht im erforderlichen Umfang zur Verfügung. Zudem fördern Koinfektionen wie Tuberkulose oder Hepatitis $\mathrm{C}$ die Entwicklung beider Erkrankungen. Dies hat in den letzten zwei Jahrzehnten weltweit auch zur einer Renaissance der Tuberkulose beigetragen. Eine Herausforderung für die kommenden Jahre liegt daher in der Entwicklung von günstigeren und leichter verfügbaren Therapien, z.B. von Vakzinen $[108,109]$, um den globalen Vormarsch der HIV-Infektion und mit ihr assoziierter Erkrankungen zu stoppen.

\section{Literatur}

1 Update: AIDS-United States 2000. MMWR 2002; 51: 592 - (http://www.cdc.gov/mmwr/preview/mmwrhtml/ mm5127a2.htm)

2 Robert Koch Institut. HIV-Infektionen und AIDS Erkrankungen in Deutschland (Stand 31.12.2003). Epidemiol Bull 2004; Sonderausgabe $A$

3 Delta: a randomised double-blind controlled trial comparing combinations of zidovudine plus didanosine or zalcitabine with zidovudine alone in HIV-infected individuals. Delta Coordinating Committee. Lancet 1996; 348: 283-291

4 Hammer SM, Katzenstein DA, Hughes MD et al. A trial comparing nucleoside monotherapy with combination therapy in HIV-infected adults with CD4 cell counts from 200 to 500 per cubic millimeter. AIDS Clinical Trials Group Study 175 Study Team. N Engl J Med 1996; 335: $1081-1090$

5 Cameron DW, Heath-Chiozzi M, Danner S et al. Randomised placebocontrolled trial of ritonavir in advanced HIV-1 disease. The Advanced HIV Disease Ritonavir Study Group. Lancet 1998; 351: 543 - 549

6 Palella Jr FJ, Delaney KM, Moorman AC et al. Declining morbidity and mortality among patients with advanced human immunodeficiency virus infection. N Engl J Med 1998; 338: $853-860$

7 Mocroft A, Ruiz L, Reiss P et al. Virological rebound after suppression on highly active antiretroviral therapy. AIDS 2003; 17: 1741 - 1751

8 Mocroft A, Katlama C, Johnson AM et al. AIDS across Europe, 1994 - 1998: the EuroSIDA study. Lancet 2000; 356: 291 - 296

9 Mellors JW, Munoz A, Giorgi JV et al. Plasma viral load and CD4+-lymphocytes as prognostic markers of HIV-1-infection. Ann Intern Med 1997; 126: 946 - 954

${ }^{10}$ Lyles RH, Munoz A, Yamashita TE et al. Natural history of human immunodeficiency virus type 1 viremia after seroconversion and proximal to AIDS in a large cohort of homosexual men. Multicenter AIDS Cohort Study. J Infect Dis 2000; 181: 872-880

11 Yeni PG, Hammer SM, Carpenter CC et al. Antiretroviral treatment for adult HIV infection in 2002: updated recommendations of the International AIDS Society-USA Panel. JAMA 2002; 288: 222 - 235
${ }^{12}$ BHIVA Writing Committee; BHIVA Executive Committee. British HIV Association (BHIVA) guidelines for the treatment of HIV-infected adults with antiretroviral therapy. HIV Med 2001; 2: 276-313

${ }^{13}$ Kahn JO, Walker BD. Acute human immunodeficiency virus type1-infection. N Engl J Med 1998; 339: 33-39

${ }^{14}$ Rosenberg ES, Altfeld M, Poon SH et al. Immune control of HIV-1 after early treatment of acute infection. Nature 2000; 407: 523-526

${ }^{15}$ Guidelines for the use of antiretroviral agents in HIV-infected adults and adolescents; http://aidsinfo.nih.gov/guidelines. 2003

${ }^{16}$ Powderly WG, Saag MS, Chapman S et al. Predictors of optimal virological response to potent antiretroviral therapy. AIDS 1999; 13: $1873-1880$

17 Mocroft A, Youle M, Moore A et al. Reasons for modification and discontinuation of antiretrovirals: results from a single treatment centre. AIDS 2001; 15: 185-194

${ }^{18}$ Schaaf B, Aries SP, Kramme E et al. Acute renal failure associated with tenofovir treatment in a patient with acquired immunodeficiency syndrome. Clin Infect Dis 2003; 37: e41-43

${ }^{19}$ Friis-Moller N, Sabin CA, Weber R et al. Combination antiretroviral therapy and the risk of myocardial infarction. N Engl J Med 2003; 349: $1993-2003$

${ }^{20}$ Petropoulos CJ, Parkin NT, Limoli KL et al. A novel phenotypic drug susceptibility assay for human immunodeficiency virus type 1 . Antimicrob Agents Chemother 2000; 44: 920-928

${ }^{21}$ Vanhove GF, Schapiro JM, Winters MA et al. Patient compliance and drug failure in protease inhibitor monotherapy. JAMA 1996; 276: $1955-1956$

22 Paterson DL, Swindells S, Mohr J et al. Adherence to protease inhibitor therapy and outcomes in patients with HIV-infection. Ann Intern Med 2000; 133: 21 - 30

${ }^{23}$ Baxter JD, Merigan TC, Wentworth DN et al. Both baseline HIV-1 drug resistance and antiretroviral drug levels are associated with shortterm virologic responses to salvage therapy. AIDS 2002; 16: $1131-1138$

24 Phillips AN, Miller V, Sabin C et al. Durability of HIV-1 viral suppression over 3.3 years with multi-drug antiretroviral therapy in previously drug-naive individuals. AIDS 2001; 15: 2379-2384

${ }^{25}$ Mezzaroma I, Carlesimo M, Pinter E et al. Clinical and immunologic response without decrease in virus load in patients with AIDS after 24 months of highly active antiretroviral therapy. Clin Infect Dis 1999; 29: $1423-1430$

${ }^{26}$ Mocroft A, Ledergerber B, Katlama C et al. Decline in the AIDS and death rates in the EuroSIDA study: an observational study. Lancet 2003; 362: $22-29$

${ }^{27}$ Stoll M, Claes C, Schulte E et al. Direct costs for the treatment of HIVinfection in a German cohort after the introduction of HAART. Eur J Med Res 2002; 7: 463-471

${ }^{28}$ Sendi PP, Bucher HC, Harr T et al. Cost effectiveness of highly active antiretroviral therapy in HIV-infected patients. Swiss HIV Cohort Study. AIDS 1999; 13: 1115-1122

${ }^{29}$ Ferrer E, Podzamczer D. Management of opportunistic infections in the era of highly active antiretroviral therapy. AIDS Rev 2000;2: $252-262$

${ }^{30}$ Brodt H, Kamps B, Gute P et al. Changing incidence of AIDS-defining illnesses in the era of antiretroviral combination therapy. AIDS 1997; 11: $1731-1738$

${ }^{31}$ Mayaud C, Cadranel J. AIDS and the lung in a changing world. Thorax 2001; 56: $423-426$

32 Wallace JM, Hansen NI, Lavange L et al. The Pulmonary Complications of HIV-Infection Study Group. Am J Respir Crit Care Med 1997; XI55: $72-80$

${ }^{33}$ Robert Koch-Institut. Bericht des Aids-Zentrums im RKI über aktuelle epidemiologische Daten, Quartalsbericht IV/98

${ }^{34}$ Sullivan Feldman C, Glatthaar M, Morar R et al. Bacteremic pneumococcal pneumonia in HIV-Seropositive and HIV-Seronegative Adults. CHEST 1999; 116: $107-114$

${ }^{35}$ Feldman C, Glatthaar M, Morar R et al. Bacteremic Pneumococcal Pneumonia in HIV-Seropositive and HIV-Seronegative Adults. CHEST 1999; 116: 107 - 114

${ }^{36}$ Baughman RP, Dohn M, Frame P. The Continuing Utility of Bronchoalveolar Lavage to Diagnose Opportunistic Infection in AIDS-Patients. Am J Med 1994; 97: 515-525

${ }^{37}$ Koch A, Kothe H, Braun J et al. Inzidenz bakterieller Pneumonien bei HIV-positiven Patienten unter Co-trimoxazol oder Pentamidin. Pneumologie 1998; 52: 614-621 
${ }^{38}$ Miller RF, Foley NM, Kessel D et al. Community acquired lobar pneumonia in patients with HIV-infection and AIDS. Thorax 1994; 49: $367-368$

${ }^{39}$ DeGarcia J, Miravitlles M, Mayordomo C et al. Empiric Treatments Impair the Diagnostic Yield of BAL in HIV-Positive Patients. CHEST 1997; 111: $1180-1186$

${ }^{40}$ Caiffa WT, Graham NMH, Vlahov D. Bacterial pneumonia in adult populations with Human Immundeficiency Virus infection. Am J Epidemiol 1993; 138: 909-922

${ }^{41}$ Saag MS, Graybill RJ, Larsen RA et al. Practice guidelines for the management of cryptococcal disease. Clin Infect Dis 2000; 30: 710-718

${ }^{42}$ Schaberg T, Dalhoff K, Ewig S et al. Empfehlungen zur Therapie der ambulant erworbenen Pneumonie. Pneumologie 1998; 52: 450-462

${ }^{43}$ Dalhoff K, Ewig S, Höffken G et al. Empfehlungen zur Diagnostik, Therapie und Prävention von Pneumonien bei erworbenem Immundefizit. Pneumologie 2002; 56: 807-831

${ }^{44}$ UNAIDS report for 2003: most deaths and new infections ever; some good news. AIDS Treat News, 2003; 3

${ }^{45}$ Colebunders R, Lambert ML. Management of co-infection with HIV and TB. Bmj 2002; 324: 802-803

${ }^{46}$ Robert Koch-Institut. Tuberkulose im Jahr 2002. Epidemiologisches Bulletin 2003; 50: 419-420

${ }^{47}$ Robert Koch-Institut. HIV-Infektionen und AIDS Erkrankungen in Deutschland. Aktuelle Epidemiologische Daten (Stand 30.06.2003). Epidemiologisches Bulletin 2003; Sonderausgabe B : 1-16

48 Bloom BR, Murray CJ. Tuberculosis: commentary on a reemergent killer. Science 1992; 257: 1055 - 1064

${ }^{49}$ Raviglione MC, Harries AD, Msiska R et al. Tuberculosis and HIV: current status in Africa. Aids 1997; 11 Suppl B : S115-123

${ }^{50}$ Havlir DV, Barnes PF. Tuberculosis in patients with human immunodeficiency virus infection. N Engl J Med 1999; 340: 367-373

51 Toossi Z. Virological and immunological impact of tuberculosis on human immunodeficiency virus type-1-disease. J Infect Dis 2003; 188: $1146-1155$

52 Ackah AN, Coulibaly D, Digbeu H et al. Response to treatment, mortality, and CD4-lymphocyte counts in HIV-infected persons with tuberculosis in Abidjan, Cote d'Ivoire. Lancet 1995; 345: 607-610

${ }^{53}$ Wood R, Maartens G, Lombard CJ. Risk factors for developing tuberculosis in HIV-1-infected adults from communities with a low or very high incidence of tuberculosis. J Acquir Immune Defic Syndr 2000; 23: $75-80$

${ }^{54}$ Toossi Z, Mayanja-Kizza H, Hirsch CS et al. Impact of tuberculosis (TB) on HIV-1-activity in dually infected patients. Clin Exp Immunol 2001; 123: $233-238$

55 Mellors JW, Rinaldo Jr CR, Gupta P et al. Prognosis in HIV-1-infection predicted by the quantity of virus in plasma. Science 1996; 272 : $1167-1170$

${ }^{56}$ Toossi Z, Johnson JL, Kanost RA et al. Increased replication of HIV-1 at sites of Mycobacterium tuberculosis infection: potential mechanisms of viral activation. J Acquir Immune Defic Syndr 2001; 28: 1-8

${ }^{57}$ Toossi Z, Nicolacakis K, Xia L et al. Activation of latent HIV-1 by Mycobacterium tuberculosis and its purified protein derivative in alveolar macrophages from HIV-infected individuals in vitro. J Acquir Immune Defic Syndr Hum Retrovirol 1997; 15: 325-331

${ }^{58}$ Mayanja-Kizza H, Wajja A, Wu M et al. Activation of beta-chemokines and CCR5 in persons infected with human immunodeficiency virus type 1 and tuberculosis. J Infect Dis 2001; 183: $1801-1804$

${ }^{59}$ Nambuya A, Sewankambo N, Mugerwa J et al. Tuberculous lymphadenitis associated with human immunodeficiency virus (HIV) in Uganda. J Clin Pathol 1988; 41: 93 -96

${ }^{60}$ Elliott AM, Halwiindi B, Hayes RJ et al. The impact of human immunodeficiency virus on presentation and diagnosis of tuberculosis in a cohort study in Zambia. J Trop Med Hyg 1993; 96: 1 - 11

${ }^{61}$ Harries AD, Maher D. TB/HIV: A clinical Manual. Geneva: WHO, 1996: 135

62 Jasmer RM, Nahid P, Hopewell PC. Clinical practice. Latent tuberculosis infection. N Engl J Med 2002; 347: 1860-1866

${ }^{63}$ Fisk TL, Hon HM, Lennox JL et al. Detection of latent tuberculosis among HIV-infected patients after initiation of highly active antiretroviral therapy. Aids 2003; 17: $1102-1104$

${ }^{64}$ Whalen C, Horsburgh Jr CR, Hom D et al. Site of disease and opportunistic infection predict survival in HIV-associated tuberculosis. Aids 1997; 11: $455-460$

65 Perlman DC, el-Sadr WM, Nelson ET et al. Variation of chest radiographic patterns in pulmonary tuberculosis by degree of human immu- nodeficiency virus-related immunosuppression. The Terry Beirn Community Programs for Clinical Research on AIDS (CPCRA). The AIDS Clinical Trials Group (ACTG). Clin Infect Dis 1997; 25: 242-246

${ }^{66}$ Espinal MA, Perez EN, Baez J et al. Infectiousness of Mycobacterium tuberculosis in HIV-1-infected patients with tuberculosis: a prospective study. Lancet 2000; 355: 275-280

${ }^{67}$ Cruciani M, Malena M, Bosco O et al. The impact of human immunodeficiency virus type 1 on infectiousness of tuberculosis: a meta-analysis. Clin Infect Dis 2001; 33: $1922-1930$

${ }^{68} \mathrm{CDC}$. Prevention and treatment of tuberculosis among patients infected with human immunodeficiency virus: principles of therapy and revised recommendations. Centers for Disease Control and Prevention. MMWR Recomm Rep 1998; 47: 1-58

${ }^{69}$ Barnes PF. Rapid diagnostic tests for tuberculosis: progress but no gold standard. Am J Respir Crit Care Med 1997; 155: 1497-1498

${ }^{70}$ Conde MB, Soares SL, Mello FC et al. Comparison of sputum induction with fiberoptic bronchoscopy in the diagnosis of tuberculosis: experience at an acquired immune deficiency syndrome reference center in Rio de Janeiro, Brazil. Am J Respir Crit Care Med 2000; 162: $2238-2240$

${ }^{71}$ Narayanswami K, Salzman SH. Bronchoscopy in the human immunodeficiency virusinfected patient. Semin Respir Infect 2003; 18: $80-86$

72 Chaisson RE, Clermont HC, Holt EA et al. Six-month supervised intermittent tubercuslosis therapy in Haitan patients with and without HIV-infection. Am J Respir Crit Care Med 1996; 154: 1034-1038

${ }^{73}$ Hung CC, Chen MY, Hsiao CF et al. Improved outcomes of HIV-1-infected abdults with tuberculosis in the era of highly active antiretroviral therapy. AIDS 2003; 17: 2615-2622

${ }^{74}$ Burman WJ, Jones BE. Treatment of HIV-related tuberculosis in the era of effective antiretroviral therapy. Am J Respir Crit Care Med 2001; 164: 7-12

${ }^{75}$ Narita M, Ashkin D, Hollender ES et al. Paradoxical worsening of tuberculosis following antiretroviral therapy in patients with AIDS. Am J Respir Crit Care Med 1998; 158: 157-161

${ }^{76}$ Updated Guidelines for the Use of Rifamycins for the Treatment of Tuberculosis Among HIV-Infected Patients Taking Protease Inhibitors or Nonnucleoside Reverse Transcriptase Inhibitors. Division of Tuberculosis Elimination, CDC, http:/www.cdc.gov/nchstp/tb/TB HIV Drugs/ TOC.htm. 2004

77 Schieferstein C, Lange C. Tuberkulose. In: Hoffmann C, Kamps BS (eds.). HIV.NET 2004. Steinhäuser Verlag, 2004: 363 - 373

78 CDC. Treatment of tuberculosis. MMWR Recomm Rep 2003; 52 $1-77$

${ }^{79}$ Dean GL, Edwards SG, Ives NJ et al. Treatment of tuberculosis in HIVinfected persons in the era of highly active antiretroviral therapy. AIDS 2002; 16: 75-83

${ }^{80}$ Schaberg T, Forssbohm M, Hauer B et al. [Guidelines for drug treatment of tuberculosis in adults and childhood]. Pneumologie 2001; 55: $494-511$

81 Pozniak A. Multidrug-resistant tuberculosis and HIV-infection. Ann N Y Acad Sci 2001; 953: $192-198$

82 Bucher HC, Griffith LE, Guyatt GH et al. Isoniazid prophylaxis for tuberculosis in HIV-infection: a meta-analysis of randomized controlled trials. Aids 1999; 13: $501-507$

${ }^{83}$ Churchyard GJ, Fielding K, Charalambous S et al. Efficacy of secondary isoniazid preventive therapy among HIV-infected Southern Africans; time to change policy? AIDS 2003; 17: 2063-2070

${ }^{84} \mathrm{CDC}$. Targeted tuberculin testing and treatment of latent tuberculosis infection. American Thoracic Society. MMWR Recomm Rep 2000; 49: $1-51$

${ }^{85}$ ATS/COC. Update: adverse event data and revised American Thoracic Society/CDC recommendations against the use of rifampin and pyrazinamide for treatment of latent tuberculosis infection-United States, 2003. MMWR Morb Mortal Wkly Rep 2003; 52: 735-739

${ }^{86}$ Nightingale SD, Byrd LT, Southern PM et al. Incidence of Mycobacterium avium-intracellulare complex bacteremia in human immunodeficiency virus-positive patients. J Infect Dis 1992; 165 (6): $1082-1085$

${ }^{87}$ Lange CG, Woolley IJ, Brodt RH. Disseminated Mycobacterium aviumintracellulare complex (MAC) infection in the era of effective antiretoviral therapy. Drugs 2004; 64: 679-692

88 Jones D, Havlir DV. Nontuberculous mycobacteria in the HIV-infected patient. Clin Chest Med 2002; 23: 665-674 
${ }^{89}$ Brown-Elliott BA, Griffith DE, Wallace RJ. Newly described or emerging human species of nontuberculous mycobacteria. Infect Dis Clin North Am 2002; 16 (1): 187-220

${ }^{90}$ ATS. Scientific assembly on microbiology, tuberculosis and pulmonary infections, American Thoracic Society. Diagnosis and treatment of disease caused by nontuberculous mycobacteria. Am J Respir Crit Care Med 1997; $156(2-2): 1-25$

${ }^{91}$ Metersky ML, Colt HG, Olson LK et al. AIDS-Related spontaneous pneumothorax, risk factors and treatment. CHEST 1995; 108: 946-951

${ }^{92}$ Cadranel J, Gillet-Juvin K, Antoine M et al. Site-directed bronchoalveolar lavage and transbronchial biopsy in HIV-infected patients with pneumonia. Am J Respir Crit Care Med 1995; 152: 1103-1106

${ }^{93}$ Jules-Elysee KM, Stover DE, Zaman MB. Aerosolized pentamidine: Effect on diagnosis and presentation of penumocystis carinii pneumonia. Ann Intern Med 1990; 112: 750 - 757

${ }^{94}$ Turner D, Schwartz Y, Yust I. Induced sputum for diagnosing Pneumocystis carinii pneumonia in HIV-patients: new data, new issues. Eur Respir J 2003; 21: 204-208

95 Sattler FR, Cowan R, Nielsen DM et al. Trimethoprim-Sulfamethoxazole compared with pentamidine for treatment of pneumocystis carinii pneumonia in the acquired immunodeficiency syndrome. Ann Intern Med 1988; 109: 280-287

${ }^{96}$ Safrin S, Lee BL, Sande MA. Adjunctive folinic acid with trimethoprim-sulfamethoxazole for pneumocystis carinii pneumonia in AIDSpatients is associated with an increased risk of therapeutic failure and death. J Infect Dis 1994; 170: 912 - 917

${ }^{97}$ Conte JE, Chernoff D, Feigal DW et al. Inhaled pentamidine for treating pneumocystis carinii pneumonia in AIDS. Ann Intern Med 1990; 113: $203-209$

${ }^{98}$ Medina I, Mills J, Leoung G et al. Oral therapy for pneumocystis carinii pneumonia in the acquired immonodeficiency syndrome. $\mathrm{N}$ Engl J Med 1990; 323: $776-782$
${ }^{99}$ Bozzette SA, Sattler FR, Chiu J et al. A controlled trial of early adjunctive treatment with corticosteroids für Pneumocyctis carinii pneumonia in the acquired immunodeficiency syndrome. N Engl J Med 1990; 323: 1451 - 1457

${ }^{100}$ Schneider MME, Hoepelman AIM, Eeftinck Schattenkerk JKM et al. A controlled trial of aerosolized pentamidine or trimethoprim-sulfamethoxazole as primary prophylaxis against pneumocystis carinii pneumonia in patients with human immunodeficiency virus infection. N Engl J Med 1992; 327: 1836-1840

${ }^{101}$ Bozette SA, Finkelstein DM, Spector SA. A randomized trial of three antipneumocystis agents in patients with advanced human immunodeficiency virus infection. N Engl J Med 1995; 332: 693-699

102 Hill HE, Wallace M, Kennedy C. Prophylaxis of pneumocystis carinii pneumonia with dapsone; an evaluation of toxicity and cross-reactivity with trimethoprim-sulfamethoxazole. International Conference on AIDS. Amsterdam, 1992: PoB. 3304

${ }^{103}$ Bucher HC, Griffith L, Guyatt GH et al. Meta-analyses of prophylactic treatments against PCP and toxoplasma.

${ }^{104}$ Afessa B, Green W, Chiao J et al. Pulmonary Complications of HIV-Infection. CHEST 1998; 113: 1225-1229

105 Waxmann A, Goldie S, Brett-Smith $\mathrm{H}$ et al. Cytomegalovirus as a primary pulmonary pathogen in AIDS. CHEST 1997; 111: 128 - 134

106 Mylonakis E, Barlam TF, Flanigan T et al. Pulmonary aspergillosis and invasive disease in AIDS. CHEST 1998; 114: 251 - 262

107 Stansell JD. Fungal disease in HIV infected persons: Cryptococcosis, histoplasmosis, and coccidioidomycosis. J Thorac Imaging 1991; 6: $28-35$

108 Vuola JM, Ristola MA, Cole B et al. Immunogenicity of an inactivated mycobacterial vaccine for the prevention of HIV-associated tuberculosis: a randomized, controlled trial. Aids 2003; 17: 2351 - 2355

109 Wahren B, Landay A. HIV immunology better understood and vaccination attempts started. Aids 2002; 16 Suppl 4: S85-88 